\title{
Heineken in the House: Improving Online Media Reputation through Featuring a Sponsored Brand Community
}

Original scientific paper __ DOI 10.22522/cmr20170117, received on 1 April 2017 UDK 316.66:004.738 658.6:796.078

$\cdots \cdots$

\section{Susan Vermeer}

Amsterdam School of Communication Research (ASCOR), University of Amsterdam, The Netherlands. Email: s.a.m.vermeer@uva.nl (corresponding author)

\section{Paola Remmelswaal}

Amsterdam School of Communication Research (ASCOR), University of Amsterdam, The Netherlands. Email: paola.remmelswaal@student.uva.nl

\section{Sandra Jacobs}

Amsterdam School of Communication Research (ASCOR), University of Amsterdam, The Netherlands. Email: s.h.j.jacobs@uva.nl

\section{Abstract}

Nowadays, more and more organizations use social media to promote their sponsorships of big events. Heineken has created a major brand community by facilitating the Holland Heineken House during the Olympic Games. This study investigates to what extent featuring a sponsored brand community on social media affected Heineken's online media reputation. A quantitative content analysis on Heineken's Facebook, Twitter and Instagram posts before, during and after the Olympic Games in 2016 was performed to analyse the relation between the promotion of the Holland Heineken House and this company's online media reputation. The use of humour, hashtags, key events and videos have been taken into account. The results show that the promotion of the Holland Heineken House positively influences Heineken's online media reputation merely on Twitter. This study thus provides valuable insights into how an organization's online media reputation can score with sponsoring a brand community.

Keywords: online media reputation; brand community; sponsoring; social media; Olympic Games; quantitative content analysis 


\section{Introduction}

Social media offer online platforms which enable thousands of users to produce and disseminate narratives about corporations. This can increase public exposure and shape corporate images (Etter, Ravasi, Colleoni, 2014). Nowadays, more and more organizations sponsor big events such as the Oscars and the Super Bowl. They do this for marketing purposes and use social media to promote these events and their sponsorship (Sneath, Finney, Close, 2005; Thackeray et al., 2008). Similarly, Heineken created a major brand community by facilitating the Holland Heineken House during the Olympic Games to show the public what Heineken as a brand stands for (Holland Heineken House, 2016). The Holland Heineken House, which is hosted by the NOC*NSF (i.e. Dutch Olympic Committee and Dutch Sports Federation), is the official national house for everyone who is involved in Dutch sports. The house welcomes 4,000 athletes and fans on a daily basis. It offers facilities to watch and practice sports, have a bite and a drink and experience the medal celebrations (Holland Heineken House, 2016).

Sponsoring popular (sports) events, such as the Super Bowl, FIFA World Cup and the Olympic Games, is costly (Apostolopoulou, Papadimitriou, 2004). It has however been argued that the notion of supporting the national effort is a key incentive to sponsor events such as the Olympic Games (Apostolopoulou, Papadimitriou, 2004). Reinforcing the national spirit can result in a positive brand image, which can eventually enhance financial returns (Wally, Hurley, 1998; Apostolopoulou, Papadimitriou, 2004). Besides having financial benefits in the long run, sponsoring has positive spillover effects on the corporate reputation and enhances corporate community relations (Wally, Hurley, 1998; Caruana, Chircop, 2000; Dean, 2002).

Online activities of organizations are assumed to contribute to image building (Gilpin, 2010) and can be beneficial for an organization's corporate reputation (Dijkmans, Kerkhof, Beukeboom, 2015). However, due to the growing use of social media, consumers are eligible to communicate publicly and, consequently, spread their thoughts about an organization (Floreddu, Cabiddu, Evaristo, 2014). When these thoughts are expressed, they can either bolster or threaten an organization's online reputation (Floreddu et al., 2014).

Responses to organizations' online media messages can generally be defined as online engagement (Dijkmans et al., 2015). Several factors evoke higher levels of online engagement. 
First of all, hashtags and images are likely to generate higher engagement scores (Kywe et al., 2012; Singh et al., 2000). Second of all, because of their salience in the news media, popular sponsorship events can automatically lead to higher civic engagement online (Pedersen et al., 2014). Accordingly, additional key events during overall big events can deliver an additional boost of attention and thus online engagement (Nichols, Mahmud, Drews, 2012). Last of all, organizations make use of humour on social media to elicit a higher level of online engagement (Liebrecht, 2015).

Though these factors are proven to affect online engagement, it remains unclear how these are able to affect an organization's online media reputation regarding sponsorship activities, directly or indirectly, through online engagement. Therefore, the research question of this study is: To what extent does featuring a sponsored brand community on social media affect an organization's online media reputation? A quantitative content analysis of Heineken's social media posts will be employed to answer this question.

\section{Online Media Reputation Management by Organizations}

Organizations carry out various online activities in the assumption that they are beneficial for their corporate reputation (Dijkmans et al., 2015). A corporate reputation is a key criterion in the supplier selection process by potential customers (Walsh et al., 2009). Besides, a favourable reputation can encourage customer loyalty and retention, enable an organization to attract more customers and generate market entry barriers for competitors (Nguyen, Leblanc, 2001). Eventually, in times of crisis, a positive reputation can protect an organization (Shamma, 2012).

Consequently, organizations are also aiming at achieving a favourable reputation online, which can be referred to as online reputation management: "the process of positioning, monitoring, measuring, talking and listening as the organization engages in a transparent and ethical dialogue with its various online stakeholders" (Jones, Temperley, Lima, 2009, p. 334). Online reputation management often focuses on various online platforms, such as blogs, wikis and social media. In particular, social media platforms have become an essential element of online reputation management, because of features that quickly help create 
significant changes in an organization's online reputation. Enhancing trustworthiness, brand attitude, and customer commitment are the most prevailing incentives for organizations to use social media (Van Noort, Willemsen, 2011). Eventually, a firm's online media reputation can be defined as its overall evaluation presented in online media, for example on Facebook, Twitter and Instagram (Deephouse, 2000).

However, social media platforms may also cause risks of reputational damage for organizations since these are no orderly one-way channels for communication but uncontrolled arenas for participation (Aula, 2010). Negative electronic word-of-mouth (eWOM) can affect a customer's brand evaluation and purchase intention in a negative way (Lee, Park, Han, 2008). The use of hashtags in organizational Twitter messages also permits people to extract the message from its original context and review this in multiple and uncontrollable ways (Albu, Etter, 2016). Since hashtags show the capacity to alter the initial message it was designed for, these may have a negative influence on an organization's identity and reputation.

\section{Online Media Reputation: Reviewing Its Antecedents}

\subsection{Online Engagement}

Online engagement has received considerable academic attention (Hollebeek, 2011; Verhoef, Reinartz, Krafft, 2010). This study focuses on the engagement concept at its most basic level. This precondition suggests that one needs to be familiar with an organization's social media activities and follow them, from which consequent expressions of online engagement behaviour towards an organization may grow (Dijkmans et al., 2015). It has been found that consumers' level of online engagement is positively related to perception of corporate reputation (Dijkmans et al., 2015). Consequently, the increasing level of online engagement determines that corporate reputation is influenced not by what organizations say or do, but by how Internet users perceive the organization's actions (Floreddu et al., 2014). Therefore, the first hypothesis can be posed as follows:

H1a: Online engagement positively influences online media reputation. 


\subsubsection{The Influence of Hashtags}

Achieving a high level of customer engagement is considered as desirable, for it may enhance an organization's reputation, purchase decisions and brand loyalty (Hollebeek, 2011). Online engagement can be enlarged by making users more familiar with an organization's social media activities (Dijkmans et al., 2015), for example through the use of hashtags (Kywe et al., 2012). On Twitter, hashtags are often used to bring multiple conversations together and facilitate a multiplicity of conversations through being retweeted by and to other users (Kywe et al., 2012). More specifically, organizations use hashtags to communicate desired identities to a wide number of internal and external audiences (Albu, Etter, 2016). Since hashtags on Twitter make it easy to search for posts by other users and widen the audience for a specific social media post, they are stated to have performative properties within an organization (Albu, Etter, 2016). Although little research has been conducted about the role and use of hashtags on Facebook and Instagram, it is expected that hashtags will be used with the same purpose and outcomes as on Twitter. Therefore, the following relationship is expected:

H1b: The use of hashtags on Facebook, Twitter and Instagram posts positively affects online engagement.

\subsubsection{The Influence of Visuals}

Moreover, previous research shows that pictorial elements in magazines are often used to increase consumers' attention (Singh et al., 2000). It is even argued that a strong visual is perhaps the most important element for capturing a reader's attention (Pieters, Wedel, 2004). To date, little research has been conducted about the effects of images in social media posts. For this reason, Rauschnabel, Praxmarer and Ivens (2012) examined how design features influence interactions with brand postings on Facebook. Since their results confirm the attractive effect of pictures, they recommend marketers who create online postings for brands to use pictures.

Nowadays, not only still images are used to create a more attractive social media post: Short clips are also used more and more, for example videos on Twitter get a 28 percent boost (Rogers, 2014). However, the effect of using still images as well as moving images on online engagement has not been established yet. This leads to the first research question: 
$R Q 1$ : To what extent does the use of still images versus the use of moving images on Facebook, Twitter and Instagram posts positively affect online engagement on these platforms?

\subsection{Salience on the Media Agenda}

Since media reputation evolves over time, it also influences what the public learns about issues or events in the news media regarding the organization (Fombrun, Shanley, 1990; Coombs, 2007). The Olympic Games are usually salient on the media agenda and this topic is, consequently, funnelled to the public agenda (Frederick, Burch, Blaszka, 2015). Roughly 187 million tweets were sent during the Olympic Games in 2016 (Filadelfo, 2016). Because of its salience, the Olympic Games became a popular topic which can lead to higher levels of online engagement (Pedersen et al., 2014). During the Youth Olympic Games 2012, 42 percent of the tweets regarding the Olympic Games were retweeted and contained at least one relevant hashtag (Pedersen et al., 2014). Hence, it is expected that social media posts of Heineken during the Olympic Games lead to higher online engagement levels than social media posts before or after the Olympic Games, which subsequently enhances Heineken's online media reputation. Therefore, the second hypothesis is as follows:

H2: Social media posts featured during the Olympic Games rather than before or after the Olympic Games, lead to a higher online engagement, which positively affects online media reputation.

\subsection{Presence of Key Events}

During the Olympic Games key incidents can evoke higher levels of engagement. Generally, a key event can be defined as a major event that can trigger a process of reconsidering one's attitudes and behaviour (Van der Waerden, Timmermans, Borgers, 2003). In this context, a key event reflects a social process, certain event or issue that could increase engagement, such as the expulsion of Yuri van Gelder or winning a golden medal. Dutch newspapers paid a lot of attention to these kinds of events. Since the Olympic Games and incidents linked to it are salient on the media agenda, the public is likely to have these incidents on their agenda as well, also in their online communication. Organizations can also incorporate these events 
in their online campaigns. When organizations anticipate on these incidents by integrating them in their social media posts, this could result in higher levels of online engagement and subsequently affect an organization's online media reputation. Therefore, the third hypothesis can be posed as follows:

H3: The appearance of key events leads to a higher online engagement, which positively affects online media reputation.

\subsection{Humorous Messages}

Humour, or "anything done or said, purposely or inadvertently, that is found to be comical or amusing” (Long, Graesser, 1988, p. 37), is increasingly used on social media. Not only by individuals, but also by organizations (Liebrecht, 2015). More specifically, 58 percent of corporate Facebook posts contain humour (Liebrecht, 2015).

Humorous advertisements, videos and messages on social media are more popular and more likely to be shared than those without humour (Berger, Milkman, 2012; McGraw, Warren, Kan, 2015). Additionally, humorous messages are often perceived as positive and more likely to be stored in memory (Gulas, Weinberger, 2006). A humorous social media message is more likely to be processed in a positive way than a non-humorous message (Liebrecht, 2015). More specifically, humorous messages elicit higher engagement scores and positive reactions (Liebrecht, 2015). Holton and Lewis (2011) analysed the use of humour in Twitter messages of journalists. Humour appeared to be positively associated with the amount of retweets. Furthermore, humorous tweets were discussed more, meaning that they were more often publicly replied than tweets without humour. Cvijikj and Michahelles (2013) examined the characteristics of Facebook content produced by organizations and the provoked levels of online engagement. They found that informative posts, humorous posts and posts which included remuneration evoke higher levels of user interaction and engagement. Yet, it remains unclear whether humour influences an organization's online media reputation directly or indirectly via online engagement. Therefore, the following research question is conducted:

RQ2: To what extent can humorous social media posts, directly or indirectly via online engagement, affect an organization's online media reputation? 
The conceptual model of this study and the related variables are portrayed in Figure 1.

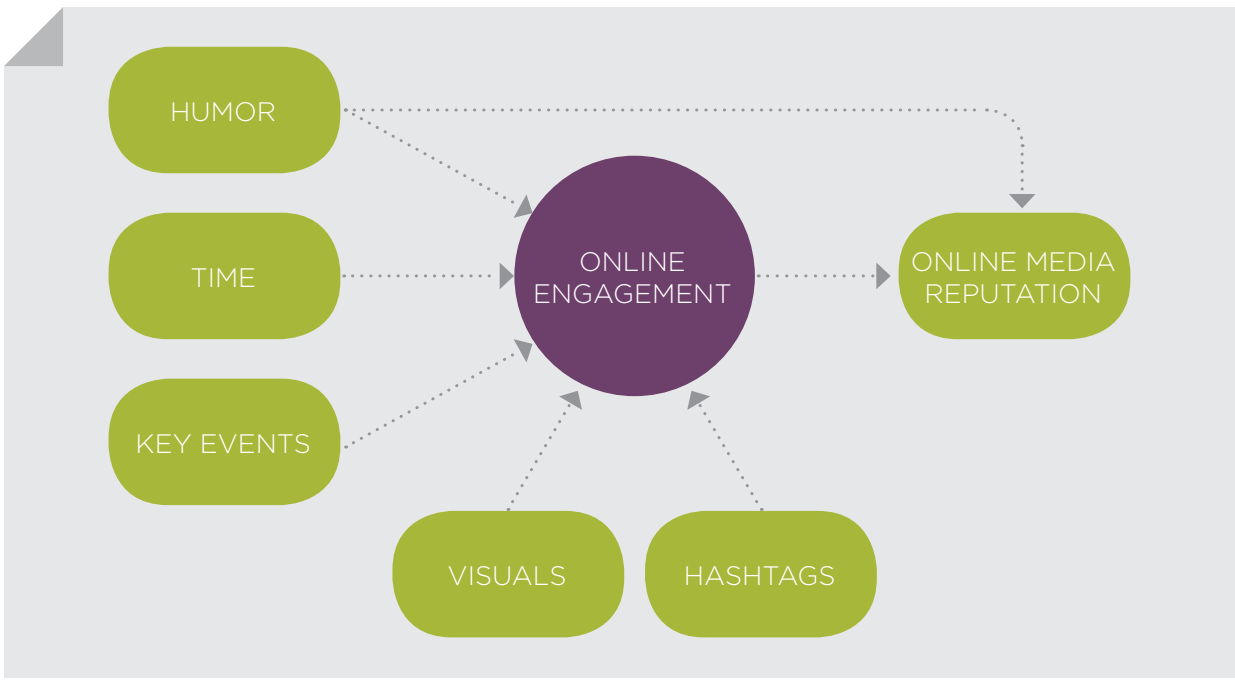

Figure 1. Conceptual model

\section{Method}

As the goal of the present study is to examine the effect of featuring a sponsored brand community on social media on an organization's online media reputation, a quantitative content analysis has been conducted.

\subsection{Case Study: Holland Heineken House}

Heineken has created a major brand community during the Olympic Games to show the public what Heineken as a brand stands for, namely the Holland Heineken House (Holland Heineken House, 2016). The Holland Heineken House is a meeting place where visitors can watch and practice sports, enjoy the Games and honour the Dutch Olympic medallists during the medal celebrations (Holland Heineken House, 2016). The official national house is hosted by the national NOC*NSF (Dutch Olympic Committee and Dutch Sports Federation) and facilitated by Heineken. During the Olympic Games in Rio de Janeiro, which took place from 5 till 21 August 2016, Heineken posted a series of posts on Facebook, Instagram and Twitter. 


\subsection{Quantitative Content Analysis}

Social media posts have been collected within three time periods, namely three weeks before (19th of July - 4th of August), during (5th of August - 21st of August), and three weeks after (22nd of August - 7th of September) the 2016 Olympic Games. In total, 28 Facebook posts, 33 Twitter posts, 22 Instagram posts and the corresponding public user comments (Twitter $\mathrm{N}=16$, Instagram $\mathrm{N}=147$, Facebook $\mathrm{N}=3220$ ) have been collected.

Four researchers coded the social media posts and the corresponding public user comments within the sample. Since Twitter does not offer a comment option, the retweets of a Twitter post have been coded instead. Besides, when a Facebook post received more than 200 comments, merely the top 200 comments have been selected for coding. A final pre-test consisting of about ten percent of the social media posts $(n=8)$ and the public user comments $(n=289)$ of the sample yielded a sufficient level of intercoder reliability (average score of Krippendorff's alpha: .787).

\subsection{Variables}

\subsubsection{Dependent Variables}

Online media reputation and online engagement are the main dependent variables. According to Grunig (2009), reputation could be measured in a content analysis by using Bromley's (1993) and Grunig and Hung's (2002) definition of reputation: What people think and say about you. More specifically, online media reputation can be found online and measured by taking into account attributes of an organization that are discussed in cyberspace (Grunig, 2009). The attributes are social media posts of Heineken and the discussion about these posts can be predominantly negative, neutral or positive, representing the tone of voice (Meijer, Kleinnijenhuis, 2006). Research on traditional media showed previously that a positive tone of voice about a company is associated with a more positive perception of corporate reputation (Meijer, Kleinnijenhuis, 2006). Hence, we argue that tone of voice is a crucial element needed to measure the online media reputation of an organization such as Heineken.

Alternative components that can be used to measure online media reputation are the number of comments, likes, shares and retweets. Nevertheless, other research proved that these 
components are viewed as online engagement factors, rather than online media reputation factors (Cvijikj, Michahelles, 2013). As stated in the theoretical background, online engagement in this study implies expressions of online engagement behaviour towards an organization (Dijkmans et al., 2015). Thus, a sharp distinction is made between online media reputation and online engagement in this study as online media reputation focuses more on the tone of voice of what people say about Heineken ( $0=$ negative, $1=$ neutral, $2=$ positive) whereas online engagement focuses more on the above-mentioned frequency factors. The online engagement score has been calculated for every platform based on the number of likes, comments, shares and retweets (Table 1).

Table 1. Descriptives Online Media Reputation

\begin{tabular}{|c|c|c|c|c|c|c|}
\hline & \multicolumn{2}{|c|}{ Facebook (main) } & \multicolumn{2}{|c|}{ Instagram (main) } & \multicolumn{2}{|c|}{ Twitter (main) } \\
\hline & $\mathbf{M}$ & SD & $\mathbf{M}$ & SD & M & SD \\
\hline Number of likes & 11076.6 & 8393.649 & 691.552 & 122.17 & 341.773 & 306.55 \\
\hline Number of shares & 1066.06 & 848.851 & & & 149.261 & 116.783 \\
\hline Number of comments & 676.027 & 416.954 & 12.781 & 5.417 & & \\
\hline Key events & .313 & & .095 & & .452 & \\
\hline Humour & .722 & & .829 & & .786 & \\
\hline Visuals & .621 & & 0 & & .464 & \\
\hline Tags & .201 & & 0 & & 0 & \\
\hline \multicolumn{7}{|l|}{ Time period } \\
\hline Before Olympic Games & .131 & & .200 & & .286 & \\
\hline During Olympic Games & .412 & & .514 & & .560 & \\
\hline After Olympic Games & .457 & & .286 & & .155 & \\
\hline \multicolumn{7}{|l|}{ Tone of Voice } \\
\hline Positive & .571 & & .867 & & .583 & \\
\hline Neutral & .093 & & .067 & & .143 & \\
\hline Negative & .325 & & .067 & & .274 & \\
\hline \multicolumn{7}{|l|}{ Control } \\
\hline Relevance & .644 & & .662 & & .714 & \\
\hline
\end{tabular}




\subsubsection{Independent Variables}

Besides being a dependent variable, online engagement is also used as an independent variable in H1a. Online engagement thus reflects the number of likes, comments, shares and retweets on every platform (Table 1). Other independent variables are the number of hashtags used, the use of still versus moving images (dummy variable: $0=$ still, $1=$ moving), the time period of the post ( 0 = before, 1 = during, 2 = after), the appearance of key events (dummy variable: $0=$ no, $1=$ yes $)$ and presence of humour (dummy variable: $0=$ no, $1=$ yes).

\subsubsection{Control Variables}

Additionally, the presence of a reference to the 2016 Olympic Games (dummy variable: $0=$ no, $1=$ yes) is taken into account as a control variable, as the impact of sport provides the vehicle for social media messages and engagement (Smith, Westerbeek, 2007).

\subsection{Analysis}

Compared to the online engagement score on Twitter $(M=163.68)$ and Instagram $(M=234.90)$, the online engagement score on Facebook ( $M=4239.23)$ was too high to take all the posts on the different social media platforms together. Therefore, the results are analysed separately for each of the three social media platforms.

An ordered logistics regression model is used to test hypothesis 1a, as the dependent variable media reputation is an ordinal variable. Hypothesis $1 \mathrm{~b}$ and RQ1 are tested using linear regression models due to the ratio outcome variable online engagement. To analyse the mediation as posed in hypothesis 2, 3 and RQ2, a hypothesized causal chain is tested with the help of several regression models, following the four step approach proposed by Baron and Kenny (1986). Step 1-3 need to account for zero-order relationship among the variables in the model. The fourth step is crucial in determining whether there is no, partial or full mediation. These steps are reflected in several paths tailored to this study and depicted in Figure 2. 


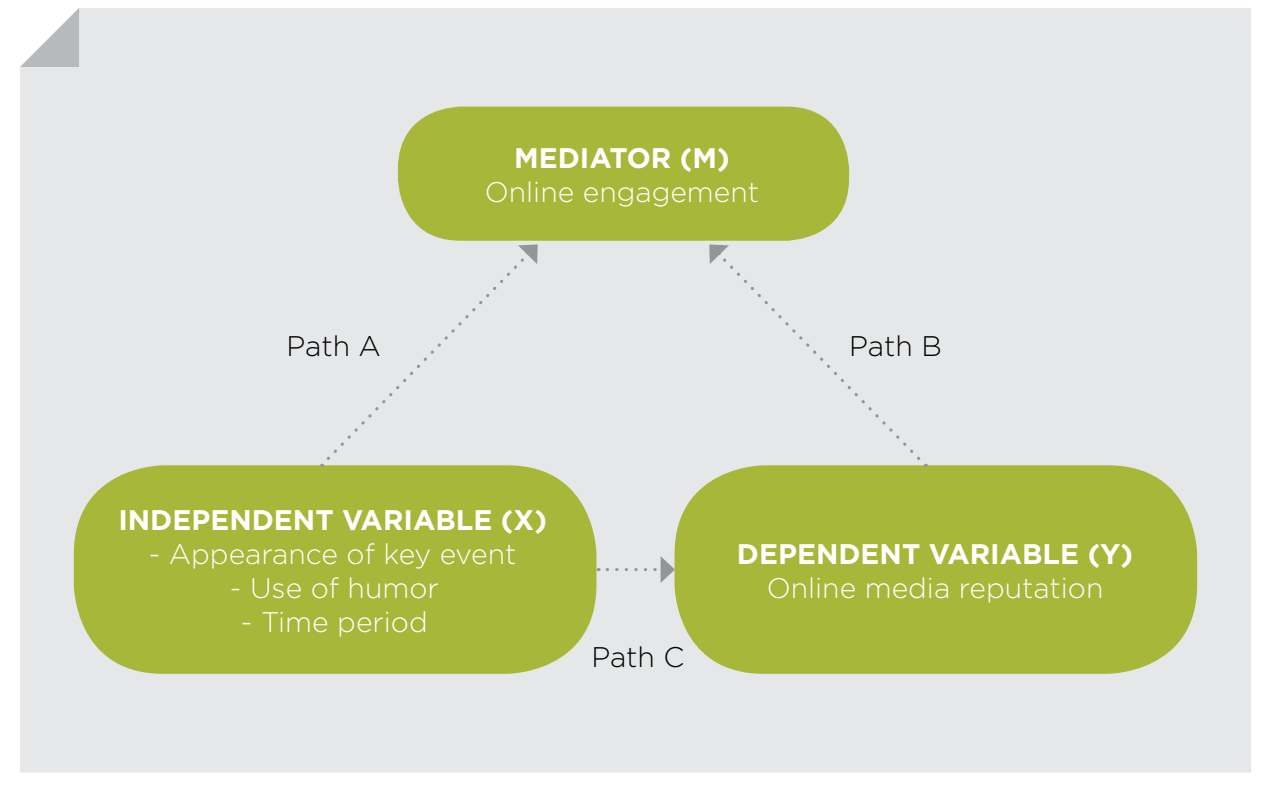

Figure 2. Paths in mediation model

\section{Results}

\subsection{Facebook}

To test whether online engagement positively influences online media reputation (H1a), an ordered logistic regression is implemented (Table 2, Model 1). The model, which has a small (McFadden's Pseudo $\mathrm{R}^{2}=.04$ ) and significant fit OR $\chi 2(6)=148.51, \mathrm{p}<.001$, shows that online engagement on Facebook positively influences online media reputation while controlling for the time of the post, key events, humour and the focus on the Olympic Games. More specifically, for each point increase in online engagement the odds of being in a higher category increase by .001. For this reason, Hypothesis 1a is accepted. 
Table 2. Ordered logistic and linear regression analyses - full models

Model 1

Online media

reputation

Facebook
Model 2

Online media

reputation

Instagram
Model 3

Online media

reputation

Twitter

B

SD

B

SD

B

SD

\section{Key predictors}

Post time

Before

$.586^{* * *}$

.187

$-1.794^{*}$

.837

1.481

.853

After

$-.452 *$

.210

.531

.939

$2.585 *$

1.254

Key events

$-.195$

.150

$-1.472$

1.473

$-.748$

.883

Humour

$-.848 * * *$

.184

.314

.984

$-.362$

.805

Online engagement

$.001 * * * *$

.000

$-.004$

.007

$.006 * *$

.002

Controls

View Olympic games

$-.753 * * *$

.193

$2.203^{*}$

.990

1.368

1.660

McFadden's Pseudo $\mathbf{R}^{2}$

N

F

Note. Significance levels are indicated with $\mathrm{p}<0.05^{*} \mathrm{p}<0.01 * \mathrm{*} \mathrm{p}<0.001^{* * * * *}$, two-tailed tests.
.128

105

13.02
.176

84

27.92

To examine to what extent still and moving images can affect online engagement (RQ1) and to test whether the use of hashtags positively affects online engagement (H1b), a linear regression is implemented (Table 3, Model 4). The explained variance is 78 percent. The model shows that both key predictors and all five control variables are significant. Results show that hashtags negatively influence online engagement on Facebook. As a result, Hypothesis $1 \mathrm{~b}$ is rejected. Regarding RQ1, using videos in Facebook posts appeared to have a positive and significant influence on engagement. This means that the use of videos has a stronger influence on online engagement than the use of images. 
Table 3. Linear regression analyses

\begin{tabular}{|c|c|c|c|c|c|c|}
\hline & \multicolumn{2}{|c|}{ Model 4} & \multicolumn{2}{|c|}{ Model 5} & \multicolumn{2}{|c|}{ Model 6} \\
\hline & \multicolumn{2}{|c|}{$\begin{array}{c}\text { Online engagement } \\
\text { Facebook }\end{array}$} & \multicolumn{2}{|c|}{$\begin{array}{l}\text { Online engagement } \\
\text { Instagram }\end{array}$} & \multicolumn{2}{|c|}{$\begin{array}{c}\text { Online engagement } \\
\text { Twitter }\end{array}$} \\
\hline & B & SD & B & SD & B & SD \\
\hline \multicolumn{7}{|l|}{ Key predictors } \\
\hline Hashtags & $-3131.29^{* * * * *}$ & 135.97 & -8.53 & 12.59 & 33.19 & 40.19 \\
\hline Video & $2549.17^{* * * * *}$ & 87.73 & & & $237.89 * * *$ & 21.12 \\
\hline \multicolumn{7}{|l|}{ Controls } \\
\hline Tag & $-1268.01^{* * * * *}$ & 95.79 & & & & \\
\hline Key event & $1058.36^{* * * *}$ & 100.36 & 17.50 & 16.68 & $75.78^{* * * *}$ & 24.10 \\
\hline Humour & $-6086.48^{* * * * *}$ & 148.08 & 1.08 & 14.60 & $66.79^{*}$ & 33.32 \\
\hline View Olympic Games & $-1990.21^{* * * * *}$ & 160.05 & -0.24 & 11.77 & -38.79 & 63.62 \\
\hline Post time & $-2033.46^{\text {****** }}$ & 106.64 & 12.05 & 9.10 & $-115.41^{* * *}$ & 20.92 \\
\hline $\mathbf{R}^{2}$ & \multicolumn{2}{|c|}{.780} & \multicolumn{2}{|c|}{.054} & \multicolumn{2}{|c|}{.714} \\
\hline $\mathbf{N}$ & \multicolumn{2}{|c|}{1848} & \multicolumn{2}{|c|}{105} & \multicolumn{2}{|c|}{84} \\
\hline $\mathbf{F}$ & \multicolumn{2}{|c|}{931.38} & \multicolumn{2}{|c|}{1.13} & \multicolumn{2}{|c|}{31.98} \\
\hline
\end{tabular}

Note. Significance levels are indicated with $\mathrm{p}<0.05^{*} \mathrm{p}<0.01^{* * *} \mathrm{p}<0.001$ *****, two-tailed tests.

\subsubsection{Mediation Effects}

In order to test whether online engagement mediates the relation between multiple independent variables (humour, the appearance of key events and the time period) and the dependent variable media reputation, several regression models have been conducted to test step 1 to 4 . 


\section{Step 1 - Path c}

First, the main effects need to be addressed, by implementing an ordered logistic regression (Table 4, Model 7), to validate path c in Figure 2. The model fit is small (McFadden' Pseudo $\left.\mathrm{R}^{2}=.04\right)$ and appears to be significant $\mathrm{OR} \chi 2(5)=131.91, \mathrm{p}<.001$. Most variables in the model turn out to have a significant effect on online media reputation. However, no significant main effect is found for the appearance of key events, which also means that no mediation effect is present. For this reason, Hypothesis 3 is rejected.

Table 4. Ordered logistic regression analyses - main effects (path c)

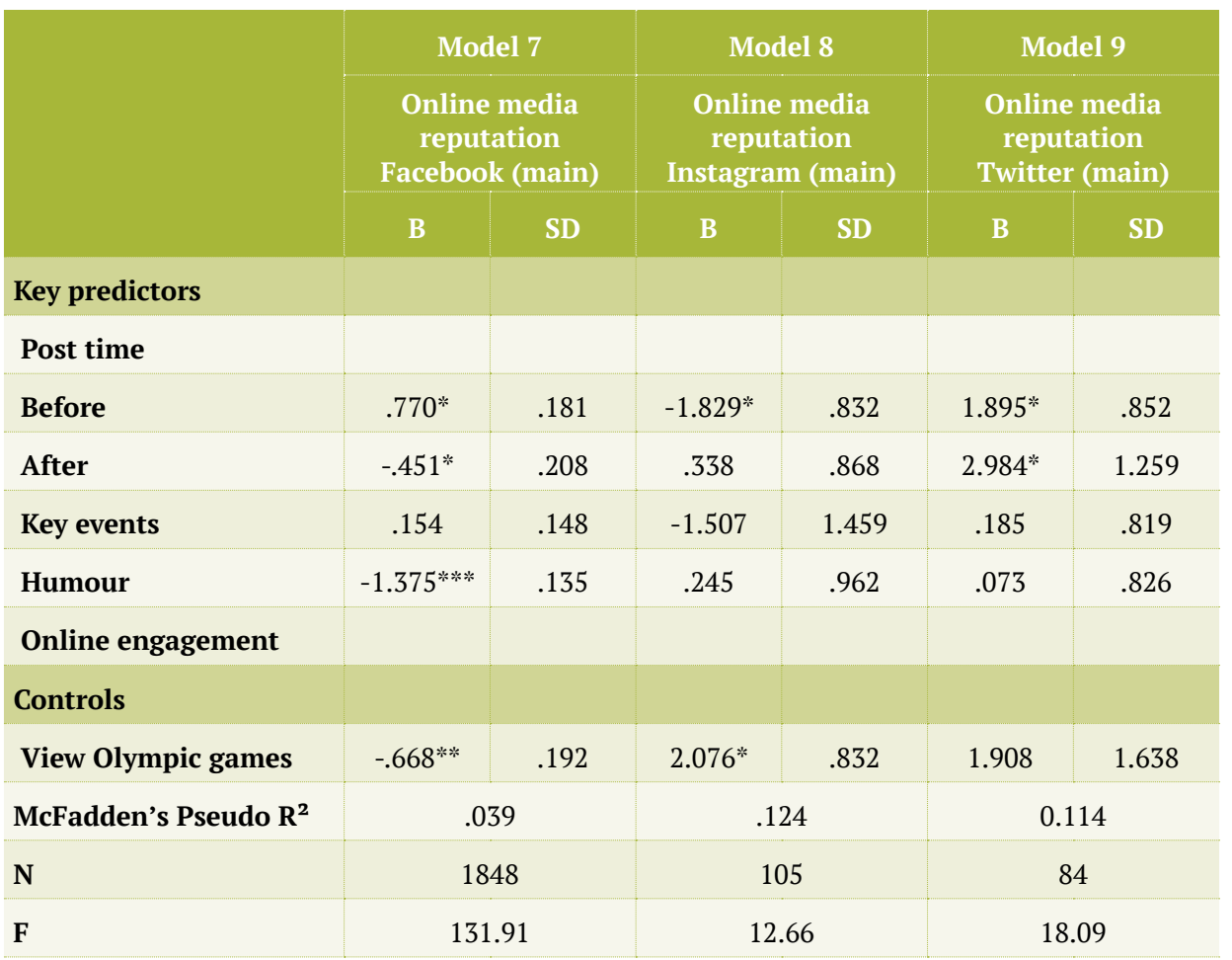

Note. Significance levels are indicated with $\mathrm{p}<0.05^{*} \mathrm{p}<0.01^{* * *} \mathrm{p}<0.001^{* * * * *}$, two-tailed tests. 
Time period on the other hand, does significantly influence online media reputation. More specifically, posts before the Olympic Games have a .77 higher log odds to be in a higher category than posts during the Olympic Games. Posts after the Olympic Games have a 45 lower log odds to be in a higher category than Posts during the Olympic Games. Thus, social media posts during the Olympic Games are more likely to elicit a favourable media reputation than posts after the Olympic Games. However, the opposite occurs when social media posts before the Olympic Games are taken into account: social media posts before the Olympic Games are more likely to elicit a favourable media reputation than posts during the Olympic Games.

Besides time period, humour also has a significant main effect on online media reputation. Humorous Facebook posts have a 1.38 lower log odds than non-humorous Facebook posts to be in a higher category, meaning that humorous Facebook posts are less likely to elicit a positive online media reputation than non-humorous Facebook posts. Hence, the first step in the causal steps process is significant, however, not completely in the expected direction. Still, the X's (time period and humour) are related to Y (online media reputation).

\section{Step 2 - Path a}

The second step in Baron and Kenny's (1986) four step approach takes into account path a: the effect of time period and humour on online engagement. A linear regression model (Table 5 , Model 10) is used as the outcome variable, online engagement, is continuous. The model explains 61 percent of all variation in online engagement. Only the posts before the Olympic Games hold a significant effect. Posts before the Olympic Games are positively related to online engagement; posts before the Olympic Games generate on average 2014.01 more online engagement points (i.e. number of likes, shares and comments) than posts during the Olympic Games. Hence, due to the insignificance of posts after the Olympic Games, only posts before the Olympic Games are taken into further consideration. The second step also proves to be significant for humour as humorous Facebook posts generate on average 5337.87 less online engagement points (i.e. number of likes, shares and comments) than non-humorous Facebook posts. 
Table 5. Linear regression analyses - Independent and mediator (path a)

Model 10

Online engagement

Facebook

B

\section{Key predictors}

Post time

\begin{tabular}{|c|c|c|c|c|c|c|}
\hline Before & $2014.006^{* * * * *}$ & 177.721 & 19.548 & 14.457 & 89.849 & 50.841 \\
\hline After & -164.289 & 193.829 & $46.971 * *$ & 14.443 & 79.109 & 60.132 \\
\hline Key events & -218.705 & 146.216 & 22.287 & 16.170 & $161.722 * *$ & 50.828 \\
\hline Humour & $-5337.867^{* * * *}$ & 114.837 & 14.976 & 14.955 & 62.792 & 49.431 \\
\hline \multicolumn{7}{|l|}{ Online engagement } \\
\hline \multicolumn{7}{|l|}{ Controls } \\
\hline View Olympic games & $958.312^{* * * *}$ & 173.434 & 22.685 & 12.866 & 107.157 & 97.171 \\
\hline $\mathbf{R}^{2}$ & \multicolumn{2}{|c|}{.610} & \multicolumn{2}{|c|}{.121} & \multicolumn{2}{|c|}{.270} \\
\hline $\mathbf{N}$ & \multicolumn{2}{|c|}{1848} & \multicolumn{2}{|c|}{105} & \multicolumn{2}{|c|}{84} \\
\hline $\mathbf{F}$ & \multicolumn{2}{|c|}{578.69} & \multicolumn{2}{|c|}{2.72} & \multicolumn{2}{|c|}{5.76} \\
\hline
\end{tabular}

Note. Significance levels are indicated with $\mathrm{p}<0.05^{*} \mathrm{p}<0.01^{* * *} \mathrm{p}<0.001$ *****, two-tailed tests.

\section{Step 3 - Path b}

In step 3, the effect of online engagement on media reputation is tested (path b). Again, an ordered logistic regression is used (Table 6, Model 13). The model fit is small (McFadden's Pseudo $\mathrm{R}^{2}=.04$ ) and significant OR $\chi 2(4)=127.83, \mathrm{p}<.001$. Online engagement, significantly and positively affects online media reputation; for each point increase on online engagement, the log odds of being in a higher category increase by .001.The same positive values are derived from a second ordered logistic regression model (Table 6, Model 14), with a small (McFadden's Pseudo $\mathrm{R}^{2}=.04$ ) and significant fit $\mathrm{OR} \chi 2(4)=126.47, \mathrm{p}<.001$, which is conducted to test path $\mathrm{b}$ regarding humour. Hence, the third step in the four step approach is confirmed for both humour and time period. 
Table 6. Ordered logistic regression analyses - Mediator and online media reputation (path b)

Model 13

Online media reputation

Facebook (time period)

B

SD
Model 14

Online media reputation

Facebook (humour)

B

SD

\section{Key predictors}

\section{Post time}

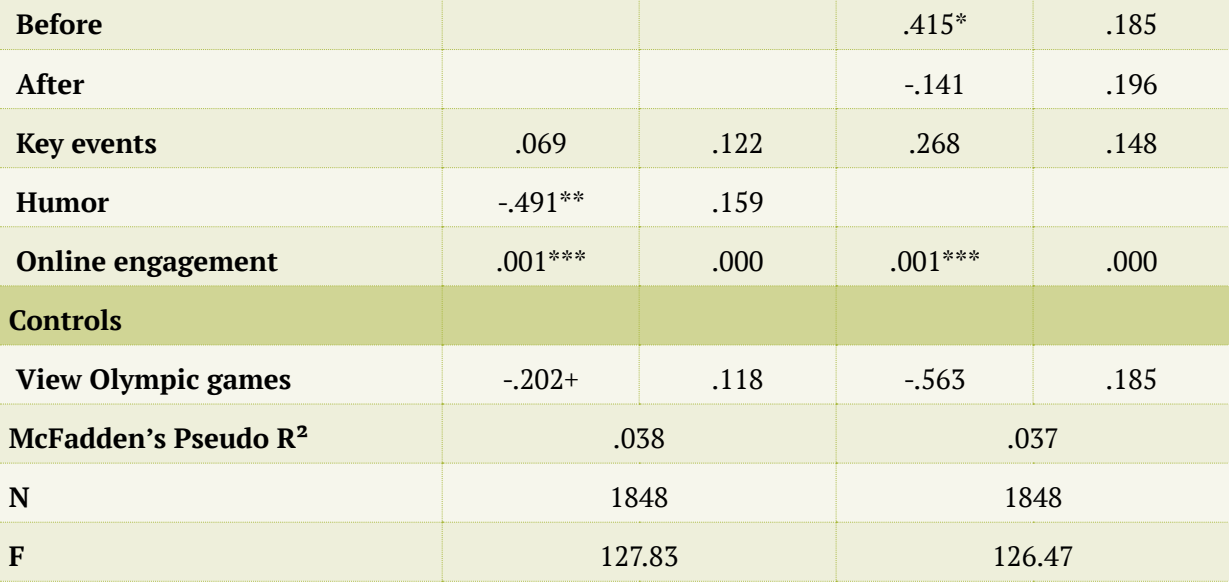

Note. Significance levels are indicated with $\mathrm{p}<0.05^{*} \mathrm{p}<0.01^{* * *} \mathrm{p}<0.001^{* * * *}$, two-tailed tests.

\section{Step 4 - Full Model}

As step 1 through 3 are proven to be significant with regards to humour and the time of the post (before), the full model can be tested in step 3, which will reveal whether a full or partial mediation is present. The ordered logistic regression model (Table 2, Model 1) is significant OR $\chi 2(6)=148.51, \mathrm{p}<.001$, and has a small model fit (McFadden's Pseudo $\left.\mathrm{R}^{2}=.04\right)$. The model shows that the time period (before) is positively associated with online media reputation. More specifically, posts before the Olympic Games are more likely to elicit a positive online media reputation than posts during the Olympic Games as posts before the Olympic Games have a .59 higher log odds to be in a higher category than posts during the Olympic Games. This is also reflected by the predicted probabilities (Figure 3). Posts before the Olympic Games 
have a higher probability to extort a positive rather than a negative online media reputation, whereas this difference is smaller for posts during the Olympic Games.

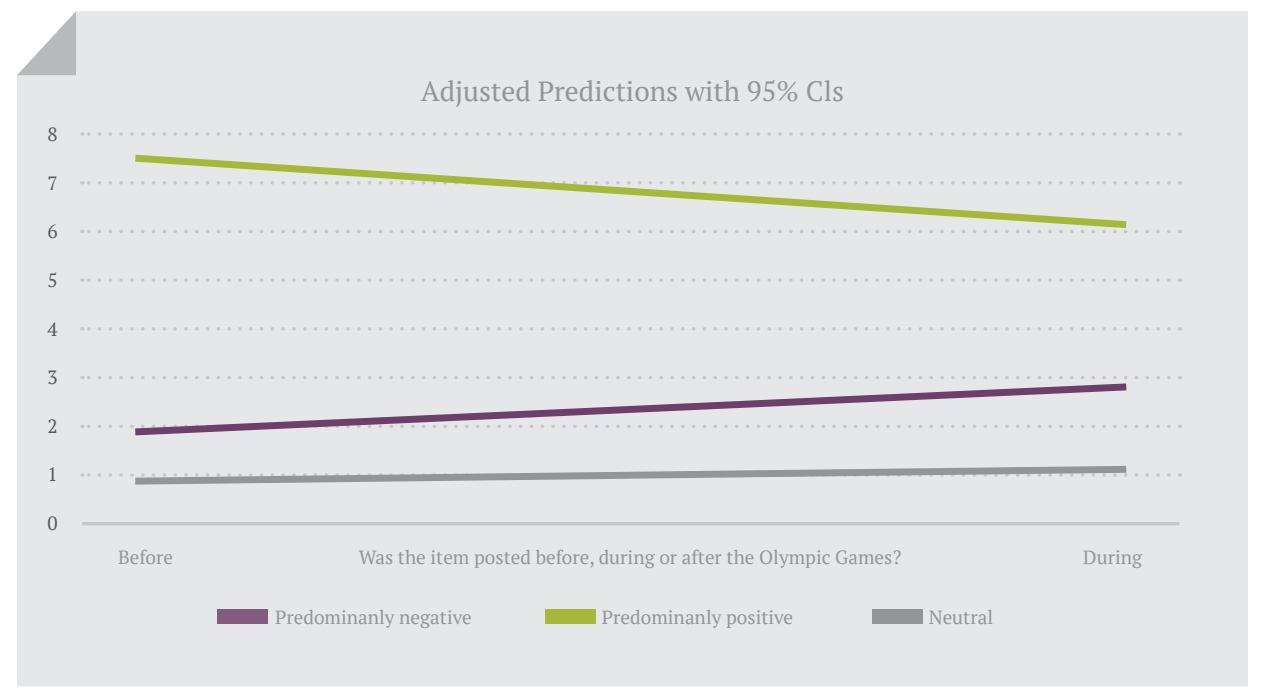

Figure 3. Predicted probabilities of the time frames on Facebook

Additionally, online engagement remains significant after controlling for time period, which indicates the presence of a mediation effect (Baron, Kenny, 1986). Online engagement is partially mediating the relationship between the time period and online media reputation, as the time period remains significant. This mediation effect only accounts for posts before the Olympic Games and not for posts after the Olympic Games in comparison to posts during the Olympic Games. Though a significant mediation effect occurred, Hypothesis 2 is rejected because of the reversed direction: posts before the Olympic Games elicit higher levels of online media reputation rather than, as previously hypothesized, lower levels of online media reputation.

Humour appears to be negatively associated with online media reputation. So, humorous Facebook posts have a .85 lower log odds than non-humorous Facebook posts to be in a higher category, meaning that humorous Facebook posts are less likely to elicit a positive online media reputation than non-humorous Facebook posts. This is also reflected by the predicted 
probabilities: non-humorous Facebook posts have a higher probability to trigger a positive online media reputation. This probability diminishes when a Facebook post is perceived as humorous, whereas the probability that a humorous post triggers a more negative online media reputation increases (Figure 4).

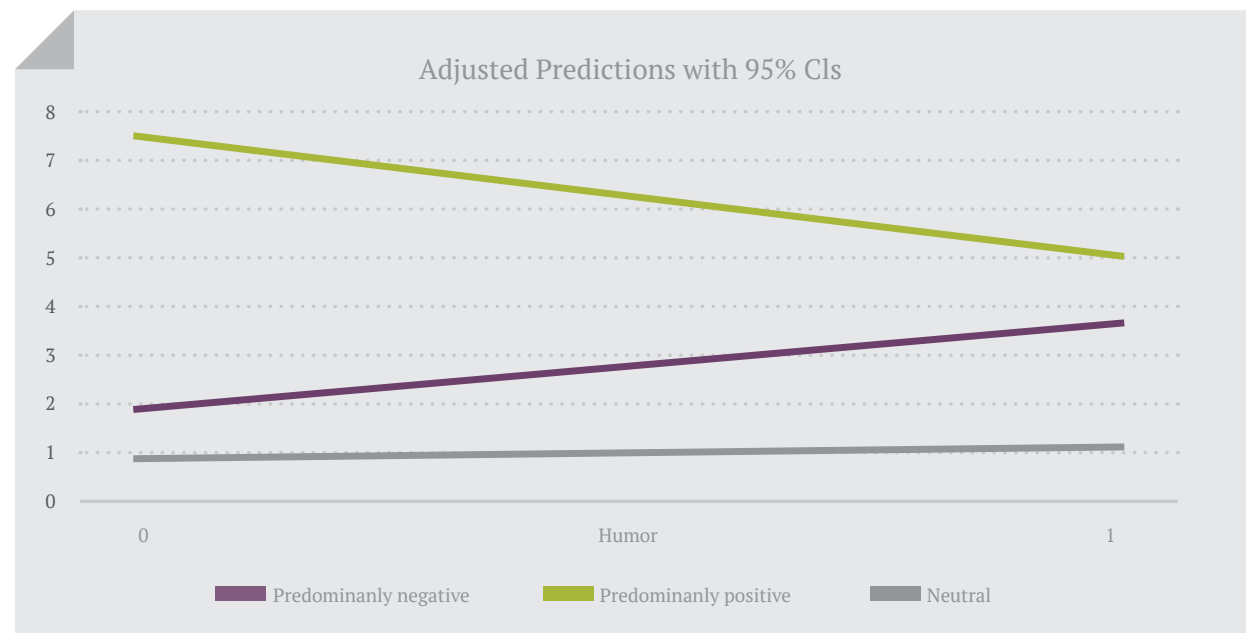

Figure 4. Predicted probabilities of humour on Facebook

As humour and online engagement are still significantly predicting media reputation, online engagement is partially mediating the relationship between humour and online media reputation on Facebook. In sum, with regards to RQ2, humorous social media posts both directly and indirectly, through online engagement, negatively affect online media reputation.

\subsection{Instagram}

To test whether online engagement on Instagram positively influences online media reputation (H1a), an ordered logistic regression is conducted (Table 2, Model 2). The model, which is significant OR $\chi 2(6)=13.02, \mathrm{p}<.05$ and has a fairly good fit (McFadden's Pseudo $\mathrm{R}^{2}=.13$ ), indicates that online engagement is not significantly influencing online media reputation. Therefore, Hypothesis 1a is rejected. 
To examine the impact of the use of still as opposed to moving images on online engagement (RQ1) and to test whether hashtags positively affect online engagement (H1b), a linear regression is conducted (Table 3, Model 5). The explained variance is 5 percent, which means that little of the effect on online engagement can be predicted by the variables included in this model. The negative effect of hashtags on online engagement is not significant. Therefore, we cannot draw conclusions on this effect and Hypothesis $1 \mathrm{~b}$ is rejected. Since the posts on Instagram did not have any videos included, no insights can be provided on RQ1 concerning this social media platform.

\subsubsection{Mediation Effects}

\section{Step 1- Path c}

First, the main effects of humour, key events and post time will be tested by implementing an ordered logistic regression analysis (Table 4, Model 8). The model fit is significant OR $\chi 2(5)=$ $12.66, \mathrm{p}<.05$ and fairly good (McFadden's Pseudo $\mathrm{R}^{2}=.12$ ). However, only posts before the Olympic Games are significantly influencing media reputation. Posts before the Olympic Games are less likely to evoke a favourable media reputation than posts during the Olympic Games as posts before the Olympic Games have a 1.83 lower log odds to be in a higher category than posts during the Olympic Games. As the first step is only significant for the time of the post (before), and not for the appearance of key events or humour, Hypothesis 3 is rejected and no conclusions can be drawn regarding the main or indirect effects of humour on online media reputation.

\section{Step 2 - Path a}

To test step 2, a linear regression model is conducted (Table 5, Model 11). The model explains 12 percent of all variations in online engagement. The time of the post (before) does not significantly influence online engagement. Therefore, as no mediation effect is possible when the second step in the causal steps process is insignificant (Baron, Kenny, 1986), Hypothesis 2 is also rejected. 


\subsection{Twitter}

The effect between online engagement on Twitter and online media reputation is tested with an ordered logistic regression analysis (Table 2, Model 3). The model fit is significant $\mathrm{OR} \chi 2(6)=27.92, \mathrm{p}<.05$ and fairly good (McFadden's Pseudo $\mathrm{R}^{2}=.18$ ). The model shows that online engagement is positively influencing online media reputation, while controlling for the time of the post, key events, humour and the focus on the Olympic Games. For each point increase on online engagement, the log odds of being in a higher category increase by .006 . Therefore, Hypothesis 1a is accepted.

To examine to what extent still and moving images can affect online engagement (RQ1) and to test whether the use of hashtags affects online engagement positively (H1b), a linear regression is conducted (Table 3, Model 6). The explained variance of this model is 71 percent. Furthermore, the model shows that significance varies for the two key predictors and control variables. Hashtags appeared to have a positive but not significant influence on online engagement. Therefore, Hypothesis $1 \mathrm{~b}$ is rejected. Finally, regarding RQ1, the use of videos has a positive, significant influence on online engagement. This means that using videos has a stronger influence on online engagement than using images.

\subsubsection{Mediation Effects}

\section{Step 1 - Path c}

Again, the main effects are tested with the help of an ordered logistic regression analysis (Table 4 , Model 9). The model fit is significant OR $\chi 2(5)=18.09, \mathrm{p}<.05$ and fairly good (McFadden's Pseudo $\mathrm{R}^{2}=.11$ ). The appearance of key events and humour remain insignificant and thus, Hypothesis 3 is rejected. Additionally, with regards to RQ2, humorous posts on Twitter do not directly or indirectly, via online engagement, affect online media reputation. Nevertheless, the time of the post is significantly influencing media reputation. More specifically, posts before the Olympic Games have a 1.90 higher odds ratio to be in a higher category than posts during the Olympic Games. Accordingly, posts after the Olympic games have a 2.98 higher odds ratio to be in a higher category than posts during the Olympic games. Hence, posts before and after the Olympic Games are more likely to elicit a favourable online media reputation than posts during the Olympic Games. 


\section{Step 2 - Path a}

Besides the fact that the main effect of the time of the post is in the opposite direction than hypothesized, no significant effect is found between the time of the post and online engagement in the tested regression model, which explains the 27 percent in the variation in online engagement (Table 5, Model 12). This step is, as earlier mentioned, crucial to depict a mediation effect (Baron, Kenny, 1986). Therefore, Hypothesis 2 is rejected.

\section{Discussion}

This study provides insights into the influence of brand community sponsoring on social media on an organization's online media reputation. Although previous research has found that online levels of engagement are positively related to the perception of an organization's reputation (Dijkmans et al., 2015), this research solely found that to be true for Twitter. This might be due to the fact that hashtags are less used on Facebook and Instagram (Albu, Etter, 2016). Furthermore, there are various motivations for retweeting, including: "to publicly agree with someone”, “to validate others' thoughts” or “as an act of loyalty or friendship” (Boyd, Golder, Lotan, 2010). However, in contrast to Twitter, Facebook and Instagram offer a comment option, which allows for a dynamic expression of thoughts and feelings without any restrictions. For the threshold to post a negative comment would be higher with retweets than with comments, this could elucidate the lower negativity levels on Twitter.

Furthermore, humour had an opposite effect than was anticipated. These posts got online during key events, like the suspension of Yuri van Gelder from the Olympic Games, which may have influenced the way they were interpreted. The circumstances in which humorous advertising is used therefore may preponderate the humour itself in influence and evoke even more envious and negative comments than it already would without humour (Beard, 2008). In this study, that led to a direct and indirect negative influence on Heineken's online media reputation. Mentioning the specific key events, for example, when a gold medal was won, did not have a significant effect in getting more engagement. 
These humorous posts were mostly reinforced with visual images to increase the customer's attention (Singh et al., 2000). Within the sample of this research there were too few posts not containing a visual element to investigate whether having either still images or moving images accompanying the post creates more online engagement. A comparison of still and moving images led to a non-significant result, but since there were more images than there were videos or GIFs, this might be an area for future research.

\subsection{Limitations and Future Research Directions}

An important limitation that needs to be acknowledged is that Heineken's number of followers on social media during the time frames (before, during and after the Olympic Games) has not been taken into account. A higher number of followers guarantees a larger audience and so a social media post is expected to be seen by more people. Ultimately, the number of followers is a main driver for increasing the likelihood of receiving likes and comments (Bakhshi, Shamma, Gilbert, 2014).

Besides, comments on social media posts are mostly on the outsides of the spectrum, being very positive or very negative. Basing media reputations on those reactions leaves out the 'silent middle' and polarizes the main opinions (Lee et al., 2014). Media reputation therefore does capture the evaluations of firms made by many different stakeholders, but this measure is

relatively coarse in that it captures only those evaluations that are made publicly (Deephouse, 2000). Future research might examine the online media reputation from the perspective of different stakeholders.

Finally, case study research, of course, is limited as to its "generalisability". Since the Holland Heineken House is a unique brand community it is difficult to replicate this study. However, future research could focus on the effects of sponsoring within the sports industry, such as the Jupiler League or the ABN Amro World Tennis Tournament, and its effects on an organization's online media reputation. Further research is required to retrieve insights into how an organization's online media reputation can score with sponsoring a brand community. 


\section{Conclusion}

The current study has been conducted to analyse to what extent featuring a sponsored brand community on social media affects an organization's online media reputation. In order to accomplish this research, Holland Heineken House is used as a brand community. A content analysis on 28 Facebook posts, 33 Twitter posts, 22 Instagram posts and the corresponding user likes and comments was performed to analyse whether the promotion of the Holland Heineken House on social media affects Heineken's online media reputation.

The results of this study show some remarkable findings. First, online engagement positively influences online media reputation just on one of the three social media platforms, namely Twitter. Second, in general, posts during the Olympic Games, as well as the use of hashtags and the appearance of key events did not increase Heineken's online engagement. In contrast to the previous mentioned concepts which had no influence, the use of videos on Facebook and Instagram instead of still images has led to an increase in online engagement. Finally, humorous social media posts also did not positively influence Heineken's online engagement and online media reputation. On Facebook, humour even negatively affected the online media reputation.

To conclude, in contrast with the expectations, the promotion of the Holland Heineken House positively influences Heineken's online media reputation merely on Twitter. This study expands our knowledge of reputation on social media. It develops a variant of the reputation concept called online media reputation.

\section{Acknowledgements}

We thank our colleagues Laura Mangnus and Lonneke van de Ven from the University of Amsterdam, who notably assisted the research. They have provided a valuable contribution to the work. 


\section{Reference List}

- Albu, O. B., Etter, M. (2016). Hypertextuality and Social Media A Study of the Constitutive and Paradoxical Implications of Organizational Twitter Use. Management Communication Quarterly, 30 (1), 5-31.

- Apostolopoulou, A., Papadimitriou, D. (2004). Welcome home: Motivations and objectives of the 2004 Grand National Olympic sponsors. Sport Marketing Quarterly, 13 (4), 180-192.

- Aula, P. (2010). Social media, reputation risk and ambient publicity management. Strategy \& Leadership, 38 (6), $43-49$.

- Baron, R. M., Kenny, D. A. (1986). The moderator-mediator variable distinction in social psychological research: Conceptual, strategic, and statistical considerations. Journal of personality and social psychology, 51 (6), 1173-1182.

- Bakhshi, S., Shamma, D. A., Gilbert, E. (2014). Faces engage us: Photos with faces attract more likes and comments on Instagram. In: Proceedings of the 32nd annual ACM conference on Human factors in computing systems (pp. 965-974).

- Beard, F. K. (2008). Advertising and audience offense: The role of intentional humor. Journal of marketing communications, 14 (1), 1-17.

- Berger, J. Milkman, K. L. (2012). What Makes Online Content Viral? Journal of Marketing Research, 49 (2), $192-205$.

- Boyd, D., Golder, S., Lotan, G. (2010, January). Tweet, tweet, retweet: Conversational aspects of retweeting on twitter. In: System Sciences (HICSS), 2010 43rd Hawaii International Conference on (pp. 1-10). IEEE.

- Bromley, D. B. (1993). Reputation, image, and impression management. Chichester, UK: John Wiley \& Sons.

- Caruana, A., Chircop, S. (2000). Measuring corporate reputation: a case example. Corporate Reputation Review, 3 (1), 43-57.

- Coombs, W. T. (2007). Protecting organization reputations during a crisis: The development and application of situational crisis communication theory. Corporate Reputation Review, 10 (3), 163-176.

- Cvijikj, I. P., Michahelles, F. (2013). Online engagement factors on Facebook brand pages. Social Network Analysis and Mining, 3 (4), 843-861.

- Dean, D. H. (2002). Associating the corporation with a charitable event through sponsorship: Measuring the effects on corporate community relations. Journal of Advertising, 31 (4), 77-87.

- Deephouse, D. L. (2000). Media reputation as a strategic resource: An integration of mass communication and resourcebased theories. Journal of management, 26 (6), 1091-1112.

- Dijkmans, C., Kerkhof, P., Beukeboom, C. J. (2015). A stage to engage: Social media use and corporate reputation. Tourism Management, 47, 58-67.

- Etter, M. A., Ravasi, D., Colleoni, E. (2014). Social Media Reputation. Academy of Management Proceedings, 1, 14340.

- Filadelfo, E. (2016, August 22). The \#Rio2016 Twitter data recap [Web log post]. Retrieved from: https://blog.twitter.com/2016/ the-rio2016-twitter-data-recap. July 15, 2017.

- Floreddu, P. B., Cabiddu, F., Evaristo, R. (2014). Inside your social media ring: How to optimize online corporate reputation. Business Horizons, 57 (6), 737-745.

- Fombrun, C., Shanley, M. (1990). What's in a name? Reputation building and corporate strategy. Academy of Management Journal, 33 (2), 233-258

- Frederick, E. L., Burch, L. M., Blaszka, M. (2015). A shift in set: examining the presence of agenda setting on Twitter during the 2012 London Olympics. Communication \& Sport, 3 (3), 312-333.

- Gilpin, D. (2010). Organizational image construction in a fragmented online media environment. Journal of Public Relations Research, 22 (3), 265-287.

- Gulas, C. S., Weinberger, M. G. (2006). Humor in advertising: A comprehensive analysis. ME Sharpe. (p. 71-75). Retrieved from: http://books.google.com/books. July 15, 2017.

- Grunig, J. E., Hung, C. J. (2002). The effect of relationships on reputation and reputation on relationships: A cognitive, behavioural study. Paper presented to the Public Relations Society of America Educator's Academy, Miami, Florida.

- Grunig, J. E. (2009). Paradigms of global public relations in an age of digitalisation. PRism, 6 (2), 1-19.

- Holland Heineken House (2016). Info. Retrieved from: https://www.hollandheinekenhouse.nl/nl/home/info/. July $15,2017$.

- Hollebeek, L. D. (2011). Demystifying customer brand engagement: exploring the loyalty nexus. Journal of Marketing Management, 27 (7-8), 785-807. 
- Holton, A. E., Lewis, S. C. (2011). Journalists, social media, and the use of humor on Twitter. Electronic Journal of Communication, $21(1 / 2)$.

- Jones, B., Temperley, J., Lima, A. (2009). Corporate reputation in the era of web 2.0: the case of Primark. Journal of Marketing Management, 25 (9-10), 927-939.

- Kywe, S. M., Hoang, T. A., Lim, E. P., Zhu, F. (2012). On recommending hashtags in twitter networks. In: International Conference on Social Informatics (pp. 337-350). Springer Berlin Heidelberg.

- Lee, J. K., Choi, J., Kim, C., Kim, Y. (2014). Social media, network heterogeneity, and opinion polarization. Journal of communication, 64 (4), 702-722.

- Lee, J., Park, D. H., Han, I. (2008). The effect of negative online consumer reviews on product attitude: An information processing view. Electronic commerce research and applications, 7 (3), 341-352.

- Liebrecht, C. (2015). Humor op Facebook: Engaged customers? Paper presented on Etmaal van de Communicatiewetenschap, Antwerp, Belgium.

- Long, D. L., Graesser, A. C. (1988). Wit and humor in discourse processing. Discourse Processes, 11 (1), 35-60.

- McGraw, A.P., Warren, C. Kan, C. (2015). Humorous Complaining. Journal of Consumer Research, 41 (5), 1153-1171.

- Meijer, M. M., Kleinnijenhuis, J. (2006). News and corporate reputation: Empirical findings from the Netherlands. Public Relations Review, 32 (4), 341-348.

- Nichols, J., Mahmud, J., Drews, C. (2012, February). Summarizing sporting events using twitter. In: Proceedings of the 2012 ACM international conference on Intelligent.

- Nguyen, N., Leblanc, G. (2001). Corporate image and corporate reputation in customers' retention decisions in services. Journal of Retailing and Consumer Services, 8 (4), 227-236.

- Pedersen, P. M., Burch, L., Eagleman, A. N., Yoon, J. (2014). Media coverage and organizational publicity of the Youth Olympic Games. In: Hanstad, D. V., Parent, M. M., Houlihan, B. (Eds.), The Youth Olympic Games (pp. 159-175). New York: Routledge.

- Pieters, R., Wedel, M. (2004). Attention capture and transfer in advertising: Brand, pictorial, and text-size effects. Journal of Marketing, 68 (2), 36-50.

- Rauschnabel, P. A., Praxmarer, S., Ivens, B. S. (2012). Social media marketing: How design features influence interactions with brand postings on Facebook. Advances in Advertising Research, 3, 153-161.

- Rogers, S. (2014). What's fuels a Tweet's engagement? [Web log post] Retrieved from: https://blog.twitter.com/2014/whatfuels-a-tweets-engagement. July 15, 2017.

- Shamma, H. M. (2012). Toward a comprehensive understanding of corporate reputation: concept, measurement and implications. International Journal of Business and Management, 7 (16), 151-169.

- Singh, S. N., Lessig, V. P., Kim, D., Gupta, R., Hocutt, M. A. (2000). Does your ad have too many pictures? Journal of Advertising Research, 40 (1-2), 11-27.

- Smith, A. C., Westerbeek, H. M. (2007). Sport as a vehicle for deploying corporate social responsibility. Journal of Corporate Citizenship, 25 (1), 43-54.

- Sneath, J. Z., Finney, R. Z., Close, A. G. (2005). An IMC approach to event marketing: The effects of sponsorship and experience on customer attitudes. Journal of Advertising Research, 45 (4), 373-381.

- Thackeray, R., Neiger, B. L., Hanson, C. L., McKenzie, J. F. (2008). Enhancing promotional strategies within social marketing programs: use of Web 2.0 social media. Health Promotion Practice, 9 (4), 338-343.

- Van der Waerden, P., Timmermans, H., Borgers, A. (2003). The influence of key events and critical incidents on transport mode choice switching behaviour: A descriptive analysis. Conference Paper presented at the 10th International Conference on Travel Behaviour Research, Lucerne, August 1015.

- Van Noort, G., Willemsen, L. M. (2011). Online damage control: the effects of proactive versus reactive webcare interventions in consumer-generated and brand-generated platforms. Journal of Interactive Marketing, 26 (3), 131-140.

- Verhoef, P. C., Reinartz, W. J., Krafft, M. (2010). Customer engagement as a new perspective in customer management. Journal of Service Research, 13 (3), 247-252.

- Wally, S., Hurley, A. E. (1998). The torch stops here: Olympic sponsorship and corporate reputation. Corporate Reputation Review, 1 (4), 343-355.

- Walsh, G., Mitchell, V. W., Jackson, P. R., Beatty, S. E. (2009). Examining the antecedents and consequences of corporate reputation: a customer perspective. British Journal of Management, 20 (2), 187-203. 


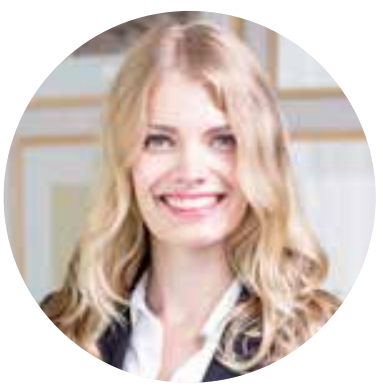

\section{Susan Vermeer}

Susan Vermeer BSc is a Research Master student in Communication Science at the University of Amsterdam. In her research, she focuses on corporate communication, including public relations and crisis communication.

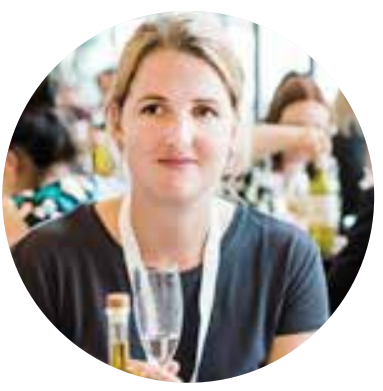

\section{Paola Remmelswaal}

Paola Remmelswaal BSc is a Research Master student in Communication Science at the University of Amsterdam. In her research, she combines corporate communication with persuasive communication.

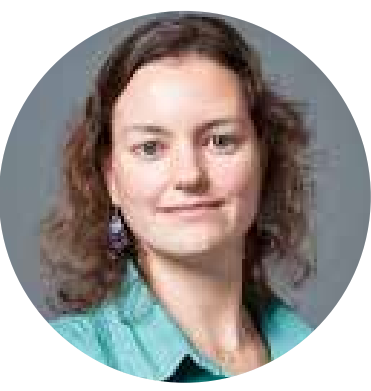

\section{Sandra Jacobs}

Sandra Jacobs $\mathrm{PhD}$ is an assistant professor in Corporate Communication at the University of Amsterdam, the Amsterdam School of Communication Research (ASCoR). In her research, she focuses on the interplay between organizations and the media. Mediatization of different types of organizations and their strategic communication are core themes in her work. 